\title{
The Development of Phyllanthus emblica Extract in Ethosomes for Hair Loss Prevention
}

\author{
Pornpun Laovachirasuwan*, Wutthichart Fuangbangluang, Atchariyaporn Phanichanaphan, Issarapong \\ Nasomroop, Methin Phadungkit
}

Pornpun Laovachirasuwan*, Wutthichart Fuangbangluang, Atchariyaporn Phanichanaphan, Issarapong Nasomroop, Methin Phadungkit

Faculty of Pharmacy, Mahasarakham University, Kantarawichai District, Mahasarakham 44150, THAILAND

\section{Correspondence}

Pornpun Laovachirasuwan

Faculty of Pharmacy, Mahasarakham University, Kantarawichai District, Mahasarakham 44150, THAILAND.

E-mail: pornpun.l@msu.ac.th

History

- Submission Date: 11-04-2020

- Review completed: 05-05-2020;

- Accepted Date: 20-05-2020;

DOI : 10.5530/pj.2020.12.128

Article Available online

http://www.phcogj.com/v12/i4

\section{Copyright}

(C) 2020 Phcogj.Com. This is an openaccess article distributed under the terms of the Creative Commons Attribution 4.0 International license.

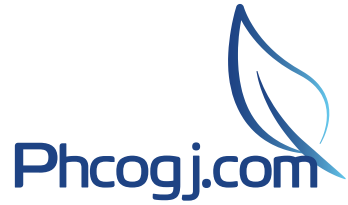

\section{ABSTRACT}

Background: Hair loss is not a serious health problem but leads to decreased self- confidence, personality, and psychological problems. According to Thai traditional medical wisdom, Phyllanthus emblica has the property to prevent hair loss. Ethosomes are a drug delivery system, which can increase drug delivery to deep skin layers and enhance the effectiveness of the active ingredient. Objective: This research aims to develop ethosomes of Phyllanthus emblica extract with beneficial properties. Materials and Methods: Phyllanthus emblica was extracted by a maceration method with 95\% ethanol as a solvent. The total phenolic content of the extracts was determined using the Folin-Ciocalteu method. The antioxidation activity was evaluated by DPPH assay. Ethosomes were formulated by a cold method and their properties were observed. Results: The results showed that the total phenolic content of Phyllanthus emblica extract was 406. 37 $\pm 2.39 \mathrm{mg} \mathrm{GAE} / \mathrm{g}$ extract. The $\mathrm{IC}_{50}$ of antioxidant activity was $7.05 \pm 0.17 \mu \mathrm{g} / \mathrm{ml}$. Ethosomes with $0.03 \%$ of Phyllanthus emblica extract, $2 \%$ of soya phosphatidylcholine, and $20 \%$ of ethanol had the highest percentage of entrapment efficiency (65. 26\% $\pm 1.80 \%$ ). The ethosomes of Phyllanthus emblica extract was the spherical shape and white colloid. The particle size, polydispersity index, zeta potential, and $\mathrm{pH}$ of ethosomes were $0.43 \pm 0.00 \mu \mathrm{m}, 0.44 \pm 0.03,-10.40 \pm 0.28 \mathrm{mV}$, and $4.06 \pm 0.03$, respectively. Conclusion: The ethosomes of Phyllanthus emblica extract had good properties and area possible alternative product for hair loss prevention.

Key words: Entrapment efficiency, Ethosomes, Phyllanthus emblica.

\section{INTRODUCTION}

Hair loss is a problem of concern for many people, both male and female. Even though hair loss is not a serious health problem, it can lead in some cases too low self-confidence, psychological problems, and even impaired quality of life. Genes and hormones are major causes of hair loss. Hair loss can be treated with discontinue behavior effect or using medicines such as finasteride and dutasteride which act as $5 \alpha$ - reductase inhibitors. Although, they are effective on hair loss prevention the use of chemical products also causes many side effects as well as altered libido, erectile dysfunction, and ejaculation disorder. ${ }^{1}$

Literature reviews report the use of many Thai traditional herbs for hair loss prevention or treatment including Phyllanthus emblica L., Citrus hystrix DC, Acacia concinna Wall., Sapindus raruk DC, Clitorea ternatea L, Averrhoa carambola L., Carthamus tinctorius L., Zingiber officinale Roscoe., Alpinia galangal Willd., Trichosanthes cucumerina L., Lawsonia inermis Linn. ${ }^{2}$

Phyllanthus emblica (P. emblica) has been used as an ancient Thai traditional medicine by maceration in water overnight before application to the scalp. Moreover, the literature reviews found that extracts of $P$. emblica have antioxidant activities ${ }^{3-5}$, stimulating proliferation of hair follicle, and inhibiting $5 \alpha$-reductase activities. ${ }^{2}$ These properties could protect from hair loss. Therefore, P. emblica may prevent hair loss but it is inconvenient to use and the exact amount required for use is not known.

Ethosomes is a novel drug delivery system that contains phospholipid, ethanol, and water. They are formed as vesicles containing P. emblica extract and can be used to increase the skin delivery to deep layers of skin, improve the systemic circulation, and enhancement of $P$. emblica extract effectiveness. This research aimed to develop ethosomes containing $P$. emblica which have good properties.

\section{MATERIALS AND METHODS}

\section{Plant material}

Phyllanthus emblica fruits were collected from $\mathrm{Na}$ dun, Maha Sarakham, Thailand. All solvents and chemicals used were analytical grade.

\section{Preparation of extract}

The 95\% ethanol of the maceration method was used as preparation P. emblica extract for 7 days at room temperature. The raw material to solvent ratio was 1:6. The extract was filtered with a Whatman No.1 filter and the filtrate was evaporated by rotary evaporator.

\section{Total phenolic content ${ }^{6}$}

The total phenolic content was determined by Folin - Ciocalteu reagent method. $20 \mu \mathrm{l}$ of stock solution

Cite this article: Laovachirasuwan $\mathrm{P}$, Fuangbangluang W, Phanichanaphan A, Nasomroop I, Phadungkit M. The Development of Phyllanthus emblica Extract in Ethosomes for Hair Loss Prevention. Pharmacogn J. 2020;12(4):905-10. 
$(0.25 \mathrm{mg} / \mathrm{ml})$ of the P. emblica extract, $100 \mu \mathrm{l}$ of $10 \%$ Folin - Ciocalteu reagent, and $80 \mu \mathrm{l}$ of $1 \mathrm{M}$ sodium carbonate solution were added to 96 well microplates and mixed well. The mixture was kept at room temperature for $30 \mathrm{~min}$ and absorbance of the color developed was recorded at $765 \mathrm{~nm}$ with UV Visible spectrophotometer (BMG Labtech, Germany). Total phenolic content estimated from 6 replicates was expressed in $\mathrm{mg}$ equivalents of gallic acid per $1 \mathrm{~g}$ of crude extract.

\section{Antioxidant activity by DPPH radical scavenging assay ${ }^{7}$}

Different 2 fold-dilution of $P$. emblica extract (stock solution $1 \mathrm{mg} /$ $\mathrm{ml})$ were prepared. 1,1-diphenyl-2-picrylhydrazyl (DPPH) solution was prepared by dissolving $6 \mathrm{mg}$ of DPPH in $100 \mathrm{ml}$ of $95 \%$ ethanol. Then $100 \mu$ of $P$. emblica extract from each dilution was added in 100 $\mu \mathrm{l}$ of DPPH solution. The mixture was shaken vigorously and left to stand in the dark condition for $30 \mathrm{~min}$. The absorbance of the solution was measured spectrophotometrically at $517 \mathrm{~nm}$ with 6 replicate measurements. The $\%$ radical scavenging of the extract was calculated using the following formula:

$\%$ radical scavenging $=\left[\left(\mathrm{Abs}_{\text {control }}-\mathrm{Abs}_{\text {sample }}\right) / \mathrm{Abs}\right.$ control $] \times 100$

Where Abs sample is the absorbance of the P. emblica extract solution and $\mathrm{Abs}$ control is the absorbance of the ascorbic acid which was used as standard.

\section{Development of ethosome formulation ${ }^{8}$}

Ethosomes were prepared by the cold method. In brief, the P. emblica extract was placed in a small round bottom flask and dissolved with $95 \%$ ethanol under mixing with the magnetic stirrer at $30^{\circ} \mathrm{C}$. The round bottom flask was covered with aluminium foil to avoid ethanol evaporation. Soya phosphatidylcholine (Phospholipon 90G) was added and dissolved. Distilled water was added slowly with a constant rate and continuous stirring to obtain the ethosomal colloidal suspensions. The suspension of ethosomes was continuously stirred for $30 \mathrm{~min}$ and the resulting formulations stored at $4^{\circ} \mathrm{C}$. The 9 formulations (F1F9) of ethosomes were prepared with varied concentrations of soya phosphatidylcholine (1-3\%) and ethanol (20-40\%). The ethosome formulations with the highest percentage of entrapment efficiency was selected. The results are shown in Table 1.

\section{Evaluation of the ethosome preparation}

The ethosome formulation which had the highest percentage of entrapment efficiency was evaluated.

\section{Morphology}

Surface morphology examined by Scanning Electron Microscopy (SEM) (FEI, Quanta 450, USA). One drop of ethosome formulation was placed on a stub and samples were dried and coated with gold before examination.

\section{pH measurement}

The $\mathrm{pH}$ of the formulations was monitored by using a digital $\mathrm{pH}$ meter (Mettler Toledo, Switzerland) with 6 replicate measurements.

\section{Particle size, size distribution, zeta potential}

Particle size, size distribution and zeta potential were measured using
Zetasizer (Malvern, UK). The size distribution was reported as the polydispersity index (PDI) with 6 replicate measurements.

\section{Total phenolic contents}

The details of total phenolic contents measurement are as mentioned above.

\section{Entrapment efficiency ${ }^{9}$}

The percentage of entrapment efficiency (\%EE) of ethosomes was determined by using the centrifugation method. $10 \mathrm{ml}$ of ethosome dispersions were centrifuged using a cooling ultracentrifuge (Beckman) at 30,000 rpm. The supernatant was siphoned off carefully to divide the unentrapped P. emblica extract. $9 \mathrm{ml}$ of $2 \%$ Triton-X 100 was added to the sediment to dissolves the vesicles. The percentage of entrapment efficiency was investigated in terms of \% GAE in sediment measured from 6 replicate measurements. The percentage of encapsulated total phenolic content was calculated as follows:

$\% \mathrm{EE}=$ (amount of GAE in ethosome / amount of GAE added) $\mathrm{x} 100$ (2)

\section{Antioxidants}

The antioxidant activity test as mentioned above.

\section{RESULTS AND DISCUSSION}

\section{Percentage of yield}

P. emblica was extracted with $95 \%$ ethanol for 7 days. After evaporation to dryness, the residue was dark brown sticky extract. The percentage of yield was $12.64 \%$.

\section{Total phenolic contents}

Total phenolic content of the P. emblica extracts was determined with the Folin-Ciocalteu method. Total phenolic contents of $P$. emblica extract were $406.37 \pm 2.39 \mathrm{mg} \mathrm{GAE} / \mathrm{g}$ crude extract $(\mathrm{n}=6)$.

\section{Ethosomes properties}

The ethosomes of Phyllanthus emblica extract had the spherical shapes and were a white colloidal suspension. The particle size, polydispersity index, zeta potential, and $\mathrm{pH}$ of $P$. emblica extracts were $1.49 \pm 0.38$ $\mu \mathrm{m}, 0.91 \pm 0.01,-34.10 \pm 0.99 \mathrm{mV}$, and $3.75 \pm 0.01$, respectively. The properties of F1-F9 ethosome formulations were as reported in Table 2. From the results, F1 ethosome formulation is the highest of a percentage of entrapment efficiency $(65.26 \pm 1.80 \% \mathrm{EE})$. The particle size, polydispersity index, zeta potential, and $\mathrm{pH}$ of the $\mathrm{F} 1$ ethosome formulation were $0.43 \pm 0.00 \mu \mathrm{m}, 0.44 \pm 0.03$, and $-10.40 \pm 0.28 \mathrm{mV}$, and $4.06 \pm 0.03$, respectively.

\section{Morphology}

SEM photographs showed the surface morphology of ethosomes. The ethosomes were revealed to be spherical vesicles with a smooth surface as shown in Figure 1.

\section{pH measurement}

The $\mathrm{pH}$ of the ethosomes formulations was between in ranges of $3.83 \pm$ 0.01 to $4.19 \pm 0.02$.

Table 1: Formulation of $P$. emblica extract in ethosomes.

\begin{tabular}{lccccccccc}
\hline Components & F1 & F2 & F3 & F4 & F5 & F6 & F7 & F8 & F9 \\
\hline P. emblica extract (mg) & 10 & 10 & 10 & 10 & 10 & 10 & 10 & 10 & 10 \\
Soya phosphatidyl choline (mg) & 600 & 600 & 600 & 900 & 900 & 900 & 1,200 & 1,200 & 1,200 \\
95\% Ethanol (ml) & 6 & 9 & 12 & 6 & 9 & 12 & 6 & 9 \\
Distilled water q.s. to (ml) & 30 & 30 & 30 & 30 & 30 & 30 & 30 & 30 & 30 \\
\hline
\end{tabular}


Table 2: The properties of $P$. emblica extracts and various ethosome formulations $(n=6)$.

\begin{tabular}{|c|c|c|c|c|c|}
\hline Formulation & $\mathrm{pH}$ & Particle size $(\mu \mathrm{m})$ & PDI & Zeta potential (mV) & $\%$ EE \\
\hline P. emblica extracts & $3.75 \pm 0.01$ & $1.49 \pm 0.38$ & $0.91 \pm 0.01$ & $-34.10 \pm 0.99$ & - \\
\hline $\mathrm{F} 1$ & $4.06 \pm 0.03$ & $0.43 \pm 0.00$ & $0.44 \pm 0.03$ & $-10.40 \pm 0.28$ & $65.26 \pm 1.80$ \\
\hline $\mathrm{F} 2$ & $3.94 \pm 0.03$ & $0.36 \pm 0.00$ & $0.37 \pm 0.02$ & $-2.17 \pm 0.10$ & $65.15 \pm 2.08$ \\
\hline F3 & $4.19 \pm 0.02$ & $0.37 \pm 0.00$ & $0.37 \pm 0.02$ & $-2.99 \pm 0.11$ & $53.48 \pm 2.06$ \\
\hline $\mathrm{F} 4$ & $4.03 \pm 0.01$ & $0.64 \pm 0.01$ & $0.79 \pm 0.04$ & $-3.33 \pm 0.12$ & $63.79 \pm 0.79$ \\
\hline F5 & $3.94 \pm 0.01$ & $1.06 \pm 0.01$ & $0.30 \pm 0.01$ & $-1.51 \pm 0.18$ & $58.97 \pm 2.17$ \\
\hline F6 & $3.96 \pm 0.02$ & $2.34 \pm 0.08$ & $0.97 \pm 0.02$ & $-0.26 \pm 0.12$ & $49.12 \pm 0.97$ \\
\hline F7 & $3.83 \pm 0.01$ & $1.49 \pm 0.06$ & $0.97 \pm 0.03$ & $-0.34 \pm 0.22$ & $58.20 \pm 1.84$ \\
\hline F8 & $4.02 \pm 0.03$ & $1.03 \pm 0.03$ & $0.45 \pm 0.02$ & $-0.24 \pm 0.33$ & $57.92 \pm 2.16$ \\
\hline F9 & $3.94 \pm 0.02$ & $1.23 \pm 0.02$ & $0.33 \pm 0.04$ & $-8.58 \pm 0.26$ & $43.34 \pm 1.69$ \\
\hline
\end{tabular}

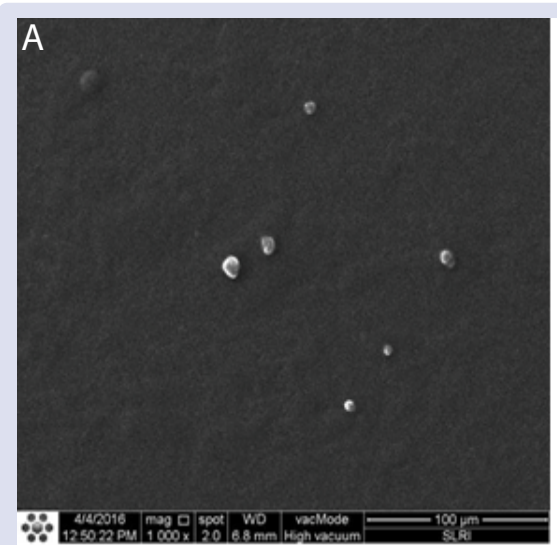

Figure 1: SEM image of ethosomes

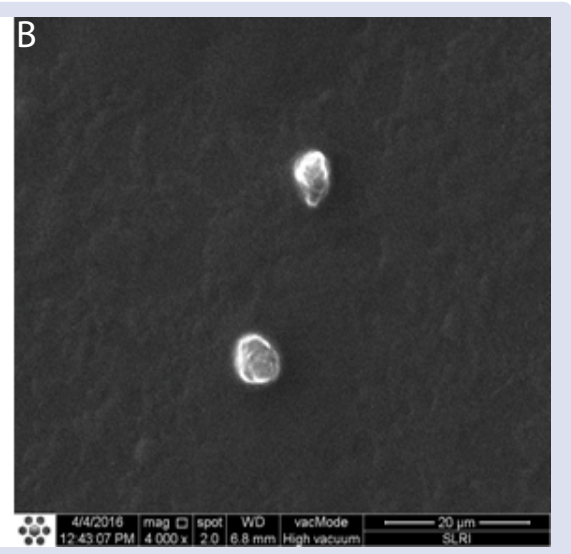

(A) (1000X) and (B) (4000X).

\section{Particle size, polydispersity index, zeta potential}

The particle size of ethosomes was in the range of $0.36 \pm 0.00$ to $2.34 \pm$ $0.08 \mu \mathrm{m}$. The polydispersity index (PDI) was $0.30 \pm 0.01$ to $0.97 \pm 0.03$ and zeta potential was $-10.40 \pm 0.28$ to $0.26 \pm 0.12 \mathrm{mV}$.

\section{Entrapment efficiency}

The percentage of entrapment efficiency (\%EE) of ethosomes formulations ranged from $43.34 \pm 1.69$ to $65.26 \pm 1.80 \%$. The F9 formulation showed minimum entrapment whereas F1 showed maximum entrapment of extract.

\section{Antioxidants}

The $\mathrm{IC}_{50}$ of $P$. emblica extracts was $7.05 \pm 0.17 \mu \mathrm{g} / \mathrm{ml}$ whereas $\mathrm{IC}_{50}$ of F1 was $1.06 \pm 0.10 \mu \mathrm{g} / \mathrm{ml}$. The $\mathrm{IC}_{50}$ of ascorbic acid which was used as standard reference was $6.42 \pm 0.20 \mu \mathrm{g} / \mathrm{ml}$.

According to the like dissolves like rule in reference to solubility of polar and non-polar substances, $95 \%$ ethanol is a very polar substance and tends to extract a high percentage of yield. This result corresponds to the result of Kornthip et al. ${ }^{10}$ who found for P. emblica bark that there was a greater percentage of yield in $95 \%$ ethanol (15.60\%) when compared with $50 \%$ ethanol (14.18\%). Moreover, a study using P. emblica from Chiang Mai produced $21.63 \%$ of crude extract when macerated with $95 \%$ ethanol. ${ }^{2}$ The different percentage of yields may be due to different sources of P. emblica.

Total phenolics contents could have been inhibitory to a $5 \alpha$-reductase enzyme which is responsible for changing androgen testosterone into the more potent androgen dihydrotestosterone (DHT). Overexpression of DHT causes androgenic alopecia in males. Therefore, we have determined average total phenolic contents of $406.37 \pm 2.39 \mathrm{mg} \mathrm{GAE} / \mathrm{g}$ crude extract which macerated in $95 \%$ ethanol for 7 days, and this corresponds to the results of Jantima et al. ${ }^{11}$ who determined total phenolic contents in P. emblica from 4 sources in Thailand extracted with ethyl acetate, and found that P. emblica from Maha Sarakham had total phenolic contents $494.00 \pm 19.50 \mathrm{mg}$ GAE/g crude extract. Although, the total phenolic contents extracted with ethyl acetate was more than that from $95 \%$ ethanol extraction, the ethyl acetate is toxic to the skin. Therefore, the research team used $95 \%$ ethanol extract in order to reduce toxicity so that the preparation can be used in dermal cosmetics.

As humans get older they produce more free radicals, while the endogenous defense mechanisms decrease. This imbalance leads to progressive damage to cellular structures. Thus, free radicals might lead to pattern baldness by damaging hair follicles. The researchers were interested in determining the antioxidant effect from $P$. emblica crude extract by the DPPH method. The $\mathrm{IC}_{50}$ was $7.05 \pm 0.17 \mu \mathrm{g} / \mathrm{ml}$ whereas the ascorbic acid standard solution had $\mathrm{IC}_{50}$ at $6.42 \pm 0.20 \mu \mathrm{g} /$ $\mathrm{ml}$, corresponding with a result from Pientaweeratch et al. ${ }^{4}$ who found the $\mathrm{IC}_{50}$ of $P$. emblica crude extract from Chaopraya Abhaiphubejhr hospital, Prachin Buri, Thailand at $1.70 \pm 0.07 \mu \mathrm{g} / \mathrm{ml}$. The different sources of $P$. emblica may cause different results.

The ethosome was proper with $30,000 \mathrm{rpm}$ at $4{ }^{\circ} \mathrm{C}$ for $90 \mathrm{~min}$ to separated sediment and supernatant parts. Then Triton X-100, a non-ionic surfactant that had no effect with total phenolic compounds analysis used as a marker in this study, was used as vesicle lysing agent for determining the percentage of entrapment efficacy. Based on the results of the study. The researchers found that increasing soya phosphatidylcholine and 95 $\%$ ethanol contents in ethosome formulations decreased the percentage of entrapment efficiency. Thus, the researchers choose F1 which had minimum soya phosphatidylcholine and $95 \%$ ethanol contents but had the highest percentage of entrapment efficiency to apply as a hair tonic. These findings were opposite to Chen et al. ${ }^{12}$ and Sivakranth et al. ${ }^{13}$ 
who found that increasing soya phosphatidylcholine and $95 \%$ ethanol contents had a greater percentage of entrapment efficiency. However, if the ethanol content was more than $45 \%$, it caused leakage of ethosome vesicles. Iizhar et al. ${ }^{14}$ found that greater entrapment efficiency was found when the ethosomes were resized by sonication. Similarly Shirwaikar et al..$^{15}$ found that a sonication effect on ethosome vesicle arrangement which increases the stability and resized the vesicle. Also, due to the vesicle size being decreased, greater permeability and deeper penetration into the target was found. While the primary study of this research shows the percentage of entrapment efficiency was decreased when the ethosomes were resized by sonication. Base on this study, the researchers found the correlation that when the concentration of phospholipid was constant and varied the concentration of ethanol. The formulations which had more ethanol contents were larger. This correlation is opposite to that reported by Touitou et al. ${ }^{16}$ who found when determining the concentration of phospholipid was constant and varied the concentration of ethanol. The formulations which had more ethanol contents were smaller. The polydispersity index of F1 formulation was $0.44 \pm 0.03$ which not more than 1 . These results showed the particles of ethosomal vesicles had distributed regularly. ${ }^{17}$ The zeta potential of F1 formulation had a more negative charge on the surface of ethosomal vesicle. F1 formulation was aggregated loosely when left overnight. However, the particles of ethosome could be quickly dispersed and suspend when shaking with a little force.

The antioxidant activity of ethosomes was greater than $P$. emblica extract solution. This study showed the development of $P$. emblica in ethosomes may improve the antioxidant activity of $P$. emblica. Koli and $\operatorname{Lin}^{18}$ reported the development of ethosomes could protect active ingredients from oxidation reactions that may promote antioxidant activity.

\section{CONCLUSION}

The combination of $20 \%$ ethanol, $2 \%$ soya phosphatidylcholine, and $P$. emblica extract $(10 \mathrm{mg})$ could be used to prepare ethosomes with good properties. The ethosomes of $P$. emblica extract can be used for hair loss prevention products.

\section{ACKNOWLEDGEMENTS}

This research was financially supported by Mahasarakham University and the Faculty of Pharmacy, Mahasarakham University.

\section{REFERENCES}

1. Zhou Z, Song S, Gao Z, Wu J, Ma J, Cui Y. The efficacy and safety of dutasteride compared with finasteride in treating men with androgenetic alopecia: a systematic review and meta-analysis. Clin Interv Aging. 2019;14:399-406.
2. Kumar N, Rungseevijitprapa W, Narkkhong NA, Suttajit M, Chaiyasut C. $5 \alpha$-reductase inhibition and hair growth promotion of some Thai plants traditionally used for hair treatment. J Ethnoplarmacol. 2012;139(3) :765-71.

3. Jantima H, Supanida W, Hathairat R. Free Radical Scavenging Capacity, Tyrosinase Inhibition Activity and Total Phenolics Content of Ethyl Acetate Extracts from Indian Gooseberry (Phyllanthus emblica L.) in Thailand. Proceedings of 48th Kasetsart University Annual Conference: Agro-Industry. 2010;91-9.

4. Pientaweeratch S, Panapisal V, Tansirikongkol A. Antioxidant, anti-collagenase and anti-elastase activities of Phyllanthus emblica, Manilkara zapota and silymarin: an in vitro comparative study for anti-aging applications. Pharm Biol. 2016;1-8.

5. Kumar MBS, Kumar MCR, Bharath AC. Screening of selected biological activities of Artocarpus lakoocha Roxb. (moraceae) fruit pericarp. J Basic Clin Pharm. 2010;1 (4) :239-45.

6. Attard E. A rapid microtitre plate Folin-Ciocalteu method for the assessment of polyphenols. Cent Eur J Biol. 2013;8(1):48-53.

7. Singh S, Prakash P. Evaluation of antioxidant activity of banana peels (Musa acuminata) extracts using different extraction methods. Chem Sci Trans. 2015;4 (1) : 158-60.

8. Sowjanya S, Shivanand K, Divakar G, Tejaswi G, Venkatanagaraju E, Swetha M. Development and In vitro evaluation of gel containing ethosomes entrapped with sulfasalazine. World J Pharm Pharm Sci. 2013;2 (6):6629-39.

9. Burapol AK, GuptaV, Ramteke S. Preparation and characterization of ethosomes for topical delivery of aceclofenac. Indian J Pharm Sci. 2010;72 (5) :582-6.

10. Kornthip P, Jinnapar B, Supakit C, Sukontip S, Sakulrat R, Pornpun L. Development of mouthwash from Phyllanthus emblica L. bark extract for oral candidiasis. Isan J Pharm Sci. 2013;9(1):151-54.

11. Jantima $H$, Supanida W, Hathairat $R$, Nakorm L, Vichai $H$. Free radical scavenging capacity, tyrosinase inhibition activity and total phenolics content of ethyl acetate extracts from Indian gooseberry (Phyllanthus emblica L.) in Thailand Proceeding of $48^{\text {th }}$ Kasetsart University Annual Conference: Agro-Industry 2010 Feb 3-5; Bangkok, Thailand; 2010. p. 1-9.

12. Chen JG, LiuYF, GaoTW. Preparation and anti-inflammatory activity of triptolide ethosomes in an erythema model. J Liposome Res. 2010;20 (4) :297-303.

13. Sivakranth M, Anjuma Ara P, Krishnaveni C, Venkatesh E. Ethosomes: a novel vesicular drug delivery system. Int J Adv Pharm 2012;2(1);16-27.

14. lizhar SA, Syed IA, Satar R. In vitro assessment of pharmaceutical potentia of ethosomes entrapped with terbinafine hydrochloride. J Adv Res. 2016;7 (3) : 453-61.

15. Shirwaikar A, Devi AS, Vipin KV, Sarat CC. Comparative evaluation of sonicated and unsonicated ethosomes containing ketoconazole. Int J Adv Pharm Biol Chem. 2012;1 (1) : 15-20.

16. Touitou E, Dayan N, Bergelson L, Godin B, Eliaz M. Ethosomes-novel vesicular carriers for enhanced delivery : characterization and skin penetration properties. J Control Release. 2000;65 (3) :403-18.

17. Esposito E, Menegatti E, Cortes R. Ethosomes and liposomes as topical vehicles for azelaic acid: A preformulation study. J Cosmet Sci. 2004;55:25364.

18. Koli JR, Lin S. Development of antioxidant ethosomes for topical delivery utilizing the synergistic properties of vit A palmitate, vit $E$ and vit $C$. AAPS J. 2009;11:1-8. 


\section{GRAPHICAL ABSTRACT}

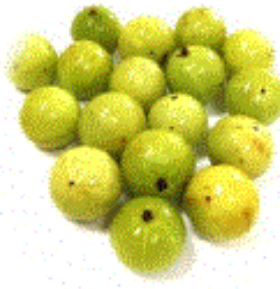

Phyllanthus emblica
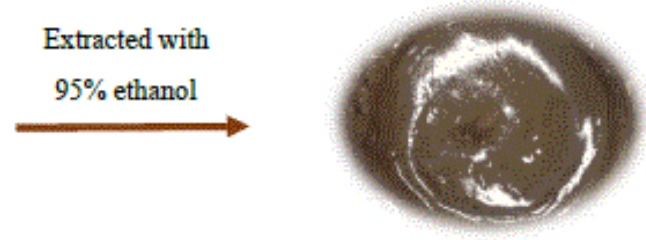

Phyllanthus emblica extract

1

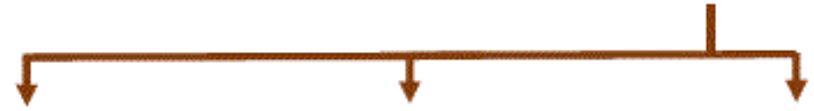

Total phenolic content by

Folin Ciocaltue method

Antioxidant activity by DPPH assay

Ethosomes by cold method
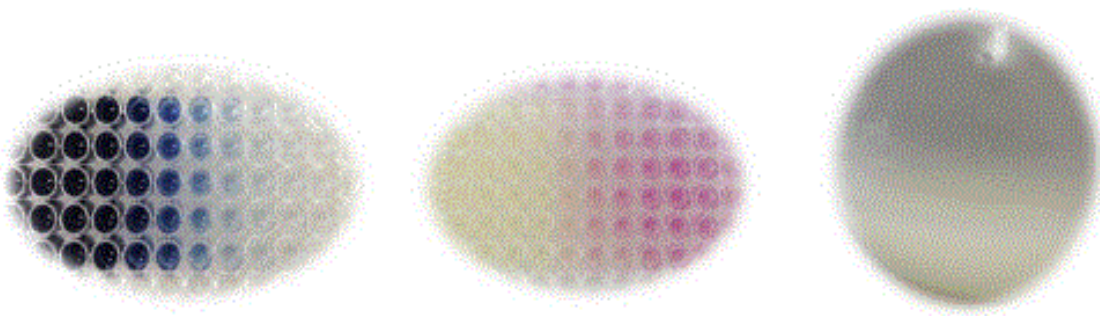

\section{ABOUT AUTHORS}

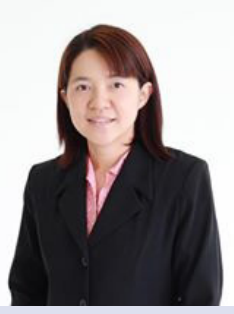

\section{Assistant Professor Dr. Pornpun Laovachirasuwan}

\section{Current affiliation:}

Faculty of Pharmacy, Mahasarakham University, Maha Sarakham, Thailand

\section{Skills and expertise:}

- Research and development of pharmaceutical, cosmeceutical, and nutraceutical product from herbal

- Drug delivery system (liposome, niosome, and ethosome)

- Biological activities (antioxidant, anti-tyrosinase, and anti-mutagenic)

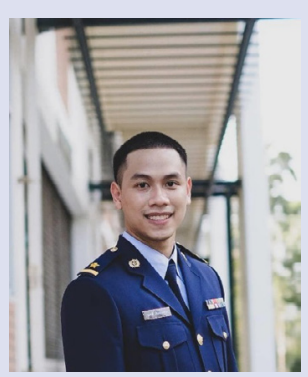

\section{Wutthichart Fuangbangluang}

\section{Current affiliation:}

Department of Pharmacy,Wing 56 hospital, Medical Royal Thai Air Force

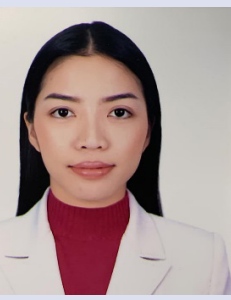

\section{Atchariyaporn Phanichanaphan \\ Current affiliation:}

Boots Retail Pharmacy, Chonburi 


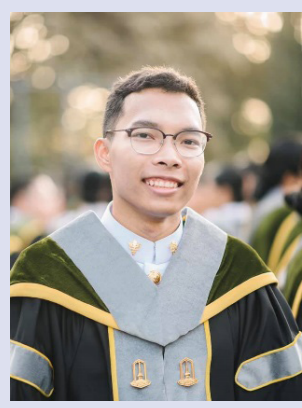

\section{Issarapong Nasomroop \\ Current affiliation:}

Department of Pharmacy, Phanomsarakham Hospital

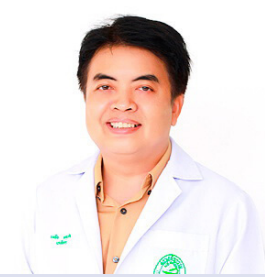

\section{Assistant Professor Dr. Methin Phadungkit Current affiliation:}

Faculty of Pharmacy, Mahasarakham University, Maha Sarakham, Thailand

Skills and expertise:

- Phytochemistry

- Biological activities (antioxidant, anti-tyrosinase, and anti-mutagenic)

- Development of herbal products

Cite this article: Laovachirasuwan P, Fuangbangluang W, Phanichanaphan A, Nasomroop I, Phadungkit M. The Development of Phyllanthus emblica Extract in Ethosomes for Hair Loss Prevention. Pharmacogn J. 2020;12(4):905-10. 